\title{
Geometrical considerations for evaluation of reserve design
}

\author{
J. Bogaert, D. Salvador-Van Eysenrode, P. Van Hecke and I. Impens
}

Bogaert, J., Salvador-Van Eysenrode, D., Van Hecke, P. and Impens, I. 2001. Geometrical considerations for evaluation of reserve design. - Web Ecol. 2: 65-70.

\begin{abstract}
The edge effect, generated by the interaction of patch and matrix, is preferably described by the interior-to-edge ratio of the patch. This ratio quantifies the extent of microclimatic changes at the boundary, and influences nature reserve design. As shown for elliptical and rectangular shapes, large and isodiametric patch designs are characterized by high interior-to-edge ratios. Different patch geometries can however lead to similar values of the ratio. A reference value, based upon the patch size, is therefore proposed to normalize the ratio to its maximum value, as observed for a perfectly isodiametric patch. The effect of patch geometry on the normalized ratio is discussed, as well as patch ranking based upon both the simple ratio and the normalized interior-to-edge ratio. An example is included using forest patches in the Belgian Campine region to illustrate the usefulness of the proposed index.
\end{abstract}

J. Bogaert (jbogaert@uia.ua.ac.be), D. Salvador-Van Eysenrode, P. Van Hecke and I. Impens, Univ. of Antwerp, UIA, Dept of Biology, Research group of Plant and Vegetation Ecology, Universiteitsplein 1, B-2610 Wilrijk, Belgium.

Habitat fragmentation is the process of breaking up continuous habitats and thereby generating habitat loss, isolation, and edge effects (Bogaert 2000). Conversion of continuous habitat into separate habitat remnants usually increases the length of the borders between fragments and their surrounding habitat (Spies et al. 1994). Isolated remnants, which were once embedded in a continuous vegetation, are consequently exposed to the contrasting physical environment of the adjacent (cleared) area (Collinge 1996). Microclimatical changes are therefore observed at the patch boundary: this is known as the "edge effect", the unaltered centre of the patch is then denoted as the "interior habitat". Edge width is determined by the penetration depth of the disturbance agent (Chen 1991, Groom and Schumaker 1993, Laurance et al. 1998), the patch orientation or exposure (Forman and Godron 1986, Saunders et al. 1991, Collinge 1996, Forman 1997) and by the type or structure of the vegetation present (Chen 1991). Considering the patch-corridor-matrix landscape model (Forman 1981, Forman and Godron 1986, Forman 1997), edge formation, generally expressed by the interior-to-edge ratio, expresses the interaction of patch and matrix. Because the relative amount of edge also is determined by patch size and shape (Forman and Godron 1986, Collinge 1996, Bogaert 2000), the interior-to-edge ratio reflects the ecological interpretation of the patch geometry. The relation with the principles for nature reserve design, as presented by Diamond (1975), is hence evident. The development of an explicit interior-to-edge ratio to prioritise between existing patches or to choose various design options is therefore important.

In this study, the effect of patch size and shape on the classic interior-to-edge ratio is described. Furthermore, a reference value is proposed to normalize the classic ratio into a new index of ecotone presence. Sensitivity of the new index to size and shape is shown. Ranking based on both indices is discussed. An example involving real data is included to illustrate the usefulness of the proposed index, its calculation and its application. 


\section{Determinants of the interior-to-edge ratio}

Shape and size effects are discussed for 2-D elliptical and rectangular shapes, because their spatial distribution of area is well defined and appropriate for illustration of interior and edge creation. Principles derived from these shapes can be extrapolated to other shapes (Forman 1981, Forman and Godron 1986).

Centripetal disturbance with constant penetration depth $\mathrm{d}$ perpendicular to all patch sides is assumed, as proposed by e.g. Laurance and Yensen (1991) and Gustafson (1998). Definition by a constant value is necessary because of the variation in frequency, impact site and penetration depth (Chen 1991, Groom and Schumaker 1993, Laurance et al. 1998) of the environmental variables or factors altering the patch microclimate. The value of $d$ is therefore considered as an average and representative value for the time-, space- and factor-dependent edge width. In analogy, recent studies report fixed $\mathrm{d}$ values to assess edge effects (e.g. Spies et al. 1994, Crow and Gustafson 1997, Donovan et al. 1997, Davidson 1998, Laurance et al. 1998). Moreover, interaction of the vegetation's structural characteristics with the disturbing agent will reduce these distances and will introduce supplementary variation on the actual edge width.

\section{Shape effects}

Consider a 2-D object (rectangular or elliptical) characterized by radii $r_{1}$ and $r_{2}$. The area $a$ is calculated as $a=r_{1} r_{2} c$ and c equals 4 or $\pi$ for rectangular and elliptical shapes respectively. If a disturbance with penetration depth $\mathrm{d}$ is present $\left(d<\left\{r_{1}, r_{2}\right\}\right)$, the ratio of interior and edge habitat area $\left(a_{i}\right.$, resp. $a_{e}$ ) is calculated by

$$
\frac{\mathrm{a}_{\mathrm{i}}}{\mathrm{a}_{\mathrm{e}}}=\frac{\left(\mathrm{r}_{1}-\mathrm{d}\right)\left(\mathrm{r}_{2}-\mathrm{d}\right)}{\mathrm{d}\left(\mathrm{r}_{1}+\mathrm{r}_{2}-\mathrm{d}\right)}
$$

For compact or isodiametric shapes $\left(r_{1} \approx r_{2} \approx r ; r / d=m\right.$; $m>1$ ), eq. (1) is simplified into

$$
\left\lfloor\frac{a_{i}}{a_{e}}\right\rfloor_{\text {is }}=\frac{(m-1)^{2}}{2 m-1}
$$

For elongated shapes $\left(r_{1} / r_{2}=k ; k>1 ; r_{2} / d=n ; n>1\right)$, eq. (1) is given by

$$
\left\lfloor\frac{\mathrm{a}_{\mathrm{i}}}{\mathrm{a}_{\mathrm{e}}}\right\rfloor_{\mathrm{el}}=\frac{(\mathrm{kn}-1)(\mathrm{n}-1)}{(\mathrm{k}+1) \mathrm{n}-1}=\frac{(\mathrm{m}(\sqrt{\mathrm{k}})-1)(\mathrm{m}-(\sqrt{\mathrm{k}}))}{(\mathrm{k}+1) \mathrm{m}-(\sqrt{\mathrm{k}})}
$$

Because only shape effects on $a_{i} / a_{e}$ are to be evaluated, $\mathrm{r}^{2}=\mathrm{kr}_{2}{ }^{2}$ and $(\mathrm{n} \sqrt{\mathrm{k}})=\mathrm{m}$. Using $(\sqrt{\mathrm{k}}-1)^{2}>0$, it can be concluded that

$$
\left\lceil\frac{a_{i}}{a_{e}}\right\rfloor_{i s}>\left\lceil\frac{a_{i}}{a_{e}}\right\rfloor_{e l}
$$

In Fig. 1, the effect of the shape factor $k$ on the observed $a_{i} / a_{e}$ is shown.

\section{Size effects}

Consider a 2-D object with radii $r_{1}$ and $r_{2}$, characterized by $\mathrm{r}_{1} / \mathrm{r}_{2}=\mathrm{k}$, and $\mathrm{k} \geq 1$. Consider a second (larger) object with radii $\mathrm{r}_{3}$ and $\mathrm{r}_{4}$, also characterized by $\mathrm{r}_{3} / \mathrm{r}_{4}=\mathrm{k}$. Let $\mathrm{a}_{1} \mathrm{z}=\mathrm{a}_{2}$ and $z>1$. Using $r_{2} / d=m$ with $m>1$, the $\left[a_{i} / a_{e}\right]_{s m}$ ratio for the smallest object is calculated by

$$
\left[\frac{\mathrm{a}_{\mathrm{i}}}{\mathrm{a}_{\mathrm{e}}}\right]_{\mathrm{sm}}=\frac{(\mathrm{km}-1)(\mathrm{m}-1)}{(\mathrm{k}+1) \mathrm{m}-1}
$$

Using $\mathrm{r}_{4} / \mathrm{r}_{2}=(\sqrt{\mathrm{z}})$ the $\left[\mathrm{a}_{\mathrm{i}} / \mathrm{a}_{\mathrm{e}}\right]_{\mathrm{gg}}$ ratio for the larger patch can be written as

$$
\left\lfloor\frac{\mathrm{a}_{\mathrm{i}}}{\mathrm{a}_{\mathrm{e}}}\right\rfloor_{\mathrm{g}}=\frac{(\mathrm{mk}(\sqrt{\mathrm{z}})-1)(\mathrm{m}(\sqrt{\mathrm{z}})-1)}{(\mathrm{k}+1) \mathrm{m}(\sqrt{\mathrm{z}})-1}
$$

Using $(b-1) x^{2}-b x+1>0$ for $x>1$ with $b=m(k+1)$ and $\mathrm{x}=(\sqrt{ } \mathrm{z})$, it can be concluded that

$$
\left[\frac{a_{i}}{a_{e}}\right]_{\mathrm{gg}}=\left[\frac{a_{i}}{a_{e}}\right]_{s m}
$$

In Fig. 2, the effect of the size factor $\mathrm{z}$ on the observed $\mathrm{a}_{\mathrm{i}} / \mathrm{a}_{\mathrm{e}}$ is shown. Note that eqs (3) and (4) confirm the statements in the seminal work of Forman (1981), i.e. large, isodiametric ("compact") patches are characterized by higher $a_{i} / a_{e}$.

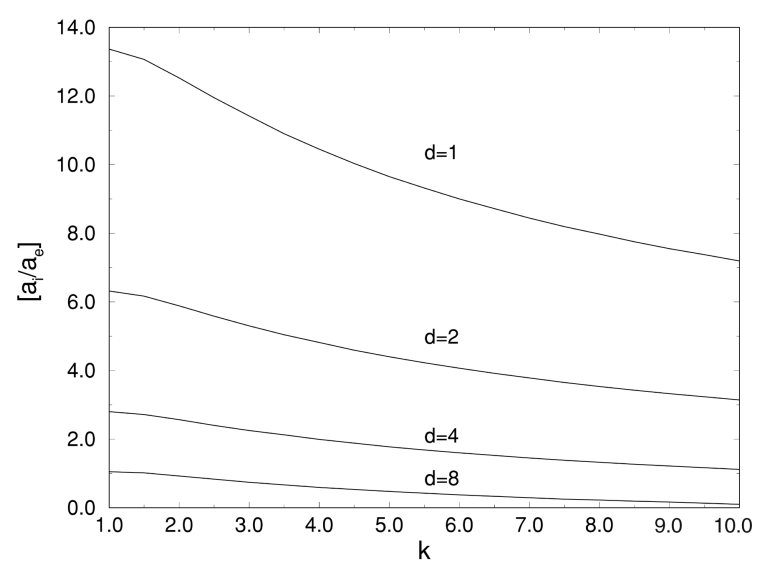

Fig. 1. Effect of disturbance penetration depth $\mathrm{d}$ and radius ratio $k$ on $a_{i} / a_{e}$ for elliptical shapes $(a=2500)$. A decrease of $a_{i} / a_{e}$ is observed for increasing $\mathrm{d}$ and $\mathrm{k}$. 


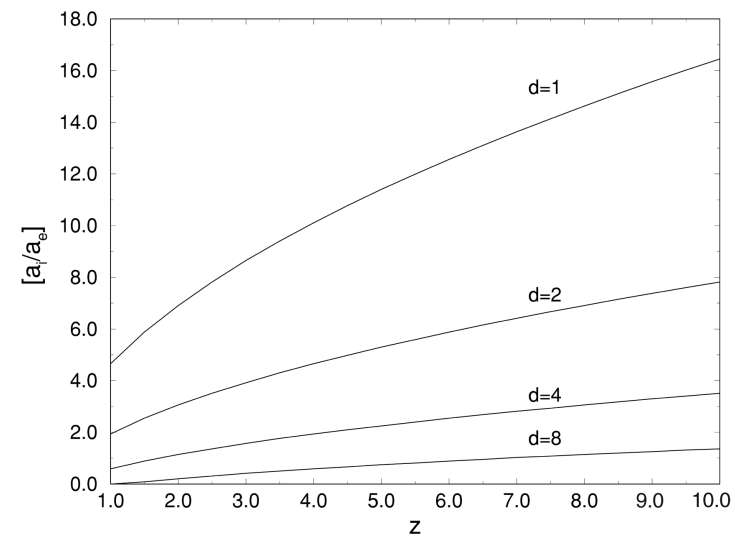

Fig. 2. Effect of disturbance penetration depth $\mathrm{d}$ and size ratio $\mathrm{z}$ on $a_{i} / a_{e}$ for elliptical shapes $(k=3)$. To calculate the actual patch size, $\mathrm{z}$ is multiplied by $500 \quad(\mathrm{z}<1 \geq \mathrm{a}<500 ; \mathrm{z}=1 \geq \mathrm{a}=500$; $z>1 \geq a>500)$. An increase of $a_{i} / a_{e}$ is observed for increasing $z$ and decreasing $\mathrm{d}$.

\section{A reference value for the interior-to- edge ratio}

Consider the shapes of Fig. 3 assumption of an equal $\mathrm{a}_{\mathrm{i}} /$ $\mathrm{a}_{\mathrm{e}}=\mathrm{v}$ and an identical disturbance depth $\mathrm{d}$ for both shapes generates

$$
\frac{\left(r_{s}-d\right)^{2}}{d\left(2 r_{s}-d\right)}=v=\frac{\left(r_{c}-d\right)^{2}}{d\left(2 r_{c}-d\right)}
$$

and consequently $r_{s}=r_{c^{c}}$. Using these radii for calculation of the actual patch sizes results in $\mathrm{a}_{s}=4 \mathrm{r}_{\mathrm{s}}^{2}>\mathrm{a}_{\mathrm{c}}=\pi \mathrm{r}_{\mathrm{c}}^{2}$. Hence, to have an equal $a_{i} / a_{e}$, the square's size has to be larger than the circle's size (mensurally, the circle will inscribe the square). The interaction of patch size and shape leads both patches to be characterized by an identical $a_{i} / a_{e}$. Therefore, $v$ should be assessed differently for both shapes. A reference value is introduced to normalize $\mathrm{a}_{\mathrm{i}} / \mathrm{a}_{\mathrm{e}}$. The interior-to-edge ratio of a regular polygon with equal area as the patch stud-

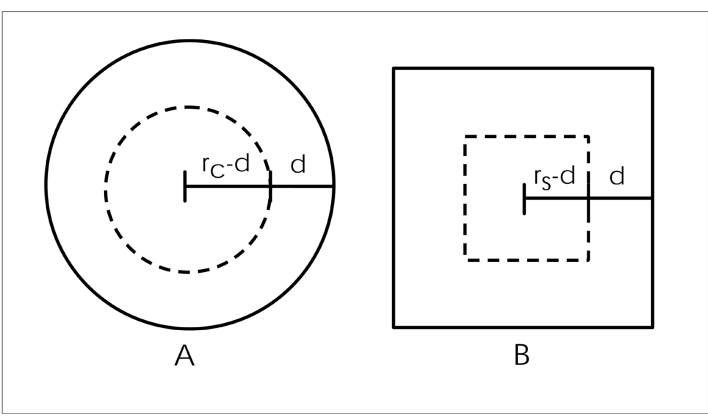

Fig. 3. The necessity of a reference value for $a_{i} / a_{e}$. A: circular shape with radius equal to $r_{c}$ and disturbance depth $d$; $B$ : square shape with radius equal to $r_{s}$ and disturbance depth $d$. Interior habitats are bounded by a dashed line. A larger area of shape B is needed to observe an equal $a_{i} / a_{e}$ for both shapes $A$ and $B$. ied but characterized by maximum shape compactness is used as reference value. The area $a_{\mathrm{r}}$ of a regular polygon with $\mathrm{n}$ sides is calculated by (Selby 1975):

$$
\mathrm{a}_{\mathrm{r}}=\mathrm{r}_{\mathrm{r}}^{2} \mathrm{n} \tan \frac{\pi}{\mathrm{n}}
$$

with $r_{r}$ the radius of the circle inscribing the regular polygon. The ratio $\left[a_{i} / a_{e}\right]_{r}$ of interior and edge (ecotone) habitat of the reference shape is then calculated by

$$
\left[\frac{a_{i}}{a_{e}}\right]_{r}=\frac{\left(r_{r}-d\right)^{2}}{d\left(2 r_{r}-d\right)}
$$

which corresponds to eq. (2). To maximize eq. (5), the perimeter of the reference polygon should be minimized, to counter edge effects. The perimeter $\mathrm{p}_{\mathrm{r}}$ of the polygon is calculated by

$$
\mathrm{p}_{\mathrm{r}}=2 \mathrm{r}_{\mathrm{r}} \mathrm{n} \tan \frac{\pi}{\mathrm{n}}
$$

Following the isoperimetric principle (Bogaert et al. 2000 ), the minimum perimeter is observed for $n \approx \infty$, i.e. a circular polygon, generating $\tan (\pi / \mathrm{n}) \approx(\pi / \mathrm{n})$. The reference polygon is then characterized by $a_{r}=r_{r}^{2} \pi, p_{r}=2 \pi r_{r}$, $a_{i}=\left(r_{r}-d\right)^{2} \pi$ and $a_{e}=d\left(2 r_{r}-d\right) \pi$.

Using $\left[a_{i} / a_{e}\right]_{r}$, an improved interior-to-edge ratio $R$ can be defined for elliptical and rectangular shapes, i.e.

with

$$
R=\frac{a_{i} / a_{e}}{\left[a_{i} / a_{e}\right]_{r}}=\frac{\left(r_{1}-d\right)\left(r_{2}-d\right)\left(2 r_{r}-d\right)}{\left(r_{r}-d\right)^{2}\left(r_{1}+r_{2}-d\right)}
$$

$$
r_{r}=\left(\sqrt{c \pi^{-1} r_{1} r_{2}}\right)
$$

When calculated for the shapes of Fig. 3, R equals unity - by definition - for the circular shape, and, for the square shape, $\mathrm{R}<1$, according to

$$
R=\frac{\left(r_{s}-d\right)^{2}\left(2 r_{r}-d\right)}{\left(r_{r}-d\right)^{2}\left(2 r_{s}-d\right)}
$$

Because $r_{r}=2 r_{s} /(\sqrt{ } \pi)$, substitution of eq. (8) leads to $R<1$ (e.g. $R \approx 0.79$ for $r_{s}=10$ and $d=4$ ). For the shapes of Fig. 3, this leads to the conclusion that - logically - the circular patch is preferred instead of the square one.

\section{Evaluation of the improved interior- to-edge ratio $R$}

\section{Shape effects}

Let $r_{1} / r_{2}=k$ and $r_{2} / d=m$ with $k>1$ and $m>1$; using eq. (7), eq. (6) can be rearranged into

$$
\mathrm{R}=\frac{(\mathrm{km}-1)(\mathrm{m}-1)\left(2 \mathrm{~m}\left(\sqrt{\mathrm{kc} \pi^{-1}}\right)-1\right)}{\left(\mathrm{m}\left(\sqrt{\mathrm{kc} \pi^{-1}}\right)-1\right)^{2}(\mathrm{~m}(\mathrm{k}+1)-1)}
$$


For isodiametric ellipses $(\mathrm{k}=1, \mathrm{c}=\pi)$, eq. (9) generates $\mathrm{R}=1$ (Fig. 4). For elongated shapes, $\mathrm{k}>>1$, it can be accepted that $(\mathrm{km}-1) \approx \mathrm{km}, \quad\left(2 \mathrm{~m}\left(\sqrt{\mathrm{kc}} \pi^{-1}\right)-1\right) \approx 2 \mathrm{~m}(\sqrt{\mathrm{kc}} \pi$ $\left.{ }^{1}\right)\left(\mathrm{m}\left(\sqrt{\mathrm{kc}} \pi^{-1}\right)-1\right) \approx \mathrm{m}\left(\sqrt{\mathrm{kc}} \pi^{-1}\right), \quad(\mathrm{m}(\mathrm{k}+1)-1) \approx \mathrm{m}(\mathrm{k}+1)$ and $(k+1) \approx k$. Equation (9) can then be rewritten as

$$
\mathrm{R} \approx \frac{2(\mathrm{~m}-1)}{\mathrm{m}\left(\sqrt{\mathrm{kc} \pi^{-1}}\right)}
$$

Hence, for $\mathrm{k} \rightarrow \infty, \mathrm{R} \rightarrow 0$. In Fig. 4 the decreasing trend of $\mathrm{R}$ as a function of $\mathrm{k}$ is shown. For $\mathrm{d}=1$, it can be accepted that $(\mathrm{m}-1) \approx \mathrm{m}$, so eq. $(10)$ is simplified into $\mathrm{R} \approx 2 /\left(\sqrt{\mathrm{kc}} \pi^{-1}\right)$. For $\mathrm{d}>>1$, eq. (10) has to be applied, which generates Rvalues lower than for $d=1$. For $d>1$ and $m \approx 1, R \approx 0$.

\section{Size effects}

Starting from eqs (6), (7) and (9), a second patch is considered with radii $r_{1}(\sqrt{z})$ and $r_{2}(\sqrt{z})$ with $z \geq 1$. R can be written as

$$
\mathrm{R}=\frac{(\mathrm{km} \sqrt{\mathrm{z}})-1(\mathrm{~m} \sqrt{\mathrm{z}})-1\left(2 \mathrm{~m}\left(\sqrt{\mathrm{kzc} \pi^{-1}}\right)-1\right.}{\left(\mathrm{m}\left(\sqrt{\mathrm{kzc} \pi^{-1}}\right)-1\right)^{2}(\mathrm{~m}(\mathrm{k}+1)(\sqrt{\mathrm{z}})-1)}
$$

For $\mathrm{z}=1$, eq. (9) is found. For $\mathrm{z}>>1$, it can be accepted that $\left(\mathrm{km}\left(\sqrt{ }_{\mathrm{z}}-1\right) \approx \mathrm{km}\left(\sqrt{\mathrm{z}}_{\mathrm{z}}-1\right), \quad\left(\mathrm{m}\left(\sqrt{ }_{\mathrm{z}}\right)-1\right) \approx \mathrm{m}\left(\sqrt{ }_{\mathrm{z}}\right), \quad\left(2 \mathrm{~m}\left(\sqrt{\mathrm{kzc}} \pi^{-1}\right)-\right.\right.$

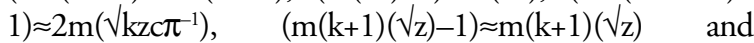
$\left(\mathrm{m}\left(\sqrt{\mathrm{kzc}} \pi^{-1}\right)-1\right) \approx \mathrm{m}\left(\sqrt{\mathrm{kzc}} \pi^{-1}\right)$. Equation (11) is then rearranged into

$$
\mathrm{R}=\frac{2(\sqrt{\mathrm{k} \pi})}{(\mathrm{k}+1)(\sqrt{\mathrm{c}})}
$$

For $\mathrm{k}=1$ and $\mathrm{c}=\pi, \mathrm{R}=1$, i.e. for perfectly compact shapes a size increase cannot increase $\mathrm{R}$. For $\mathrm{k}>>1,(\mathrm{k}+1) \approx \mathrm{k}$ and $R \approx 2(\sqrt{\pi}) /(\sqrt{k c})$, i.e. $R \rightarrow 0$ for $k \rightarrow \infty$ because the radius ratio of studied shape $(\mathrm{k}>>1)$ and reference shape $(\mathrm{k}=1)$ become extremely different. In Fig. 5, all curves increase

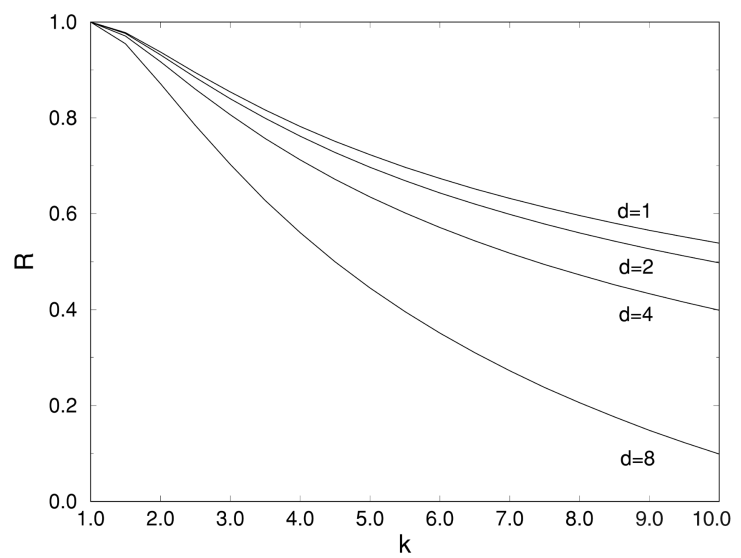

Fig. 4. Effect of disturbance penetration depth $\mathrm{d}$ and radius ratio $\mathrm{k}$ on $\mathrm{R}$ for elliptical shapes $(\mathrm{a}=2500)$. An increase of $\mathrm{k}$ and/or an increase of $d$ is associated with a decrease of $R$. For large $d$ and for $\mathrm{k}$ different from unity, $\mathrm{R}$ will never equal unity. The influence of $\mathrm{d}$ is limited for $\mathrm{k} \rightarrow 1$.

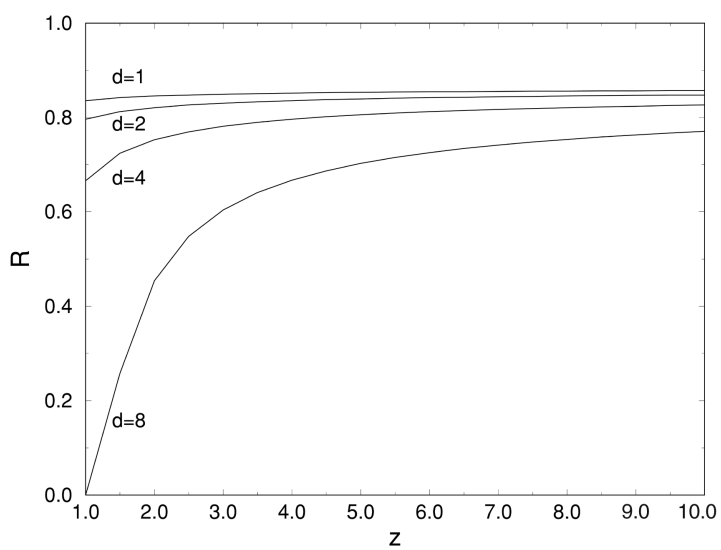

Fig. 5. Effect of disturbance penetration depth $\mathrm{d}$ and size ratio $\mathrm{z}$ on $\mathrm{R}$ for elliptical shapes $(\mathrm{k}=3)$. To calculate the actual patch size, $\mathrm{z}$ is multiplied by $500(\mathrm{z}<1 \geq \mathrm{a}<500 ; \mathrm{z}=1 \geq \mathrm{a}=500 ; \mathrm{z}>1 \geq \mathrm{a}>500)$. For $\mathrm{z}>>1, \mathrm{R} \approx 2(\sqrt{ } 3) / 4 \approx 0.87$.

and tend towards $\mathrm{R} \approx 0.87$, which correspondents to eq. (12) for $\mathrm{k}=3$ and $\mathrm{c}=\pi$. For small $\mathrm{z}$ and constant $\mathrm{k}, \mathrm{R}$ is determined by $\mathrm{m}$. Because $\mathrm{m}$ decreases with increasing $\mathrm{d}$, the lower values are found for $\mathrm{d}=8$ in Fig. 5 .

\section{Patch ranking}

In this subsection, the occurrence of different rankings for $a_{i} / a_{e}$ compared with $R$ are discussed. Consider two patches characterized by $a_{1}=r_{1} r_{2} c,\left[a_{i} / a_{e}\right]_{1}, a_{2}=r_{3} r_{4} c$, and $\left[a_{i} / a_{e}\right]_{2}$. The reference values for both patches are given by:

$$
\left[\frac{a_{i}}{a_{e}}\right]_{1, r}=\frac{\left(r_{a}-d\right)^{2}}{d\left(2 r_{a}-d\right)} \quad\left[\frac{a_{i}}{a_{e}}\right]_{2, r}=\frac{\left(r_{b}-d\right)^{2}}{d\left(2 r_{b}-d\right)}
$$

using eq. (7) for $r_{a}$ and $r_{b}$. If $\left[a_{i} / a_{e}\right]_{1}$ equals $\left[a_{i} / a_{e}\right]_{2}$, a difference in ranking will be observed if $\mathrm{R}_{1}>\mathrm{R}_{2}$. Mathematically, this can be described by

$$
\frac{2 r_{a}-d}{\left(r_{a}-d\right)^{2}}>\frac{2 r_{b}-d}{\left(r_{b}-d\right)^{2}}
$$

and eq. (13) can be simplified into

$$
\frac{2 r_{a} r_{b}}{r_{a}+r_{b}}>d
$$

which is valid for every $r_{a} \neq r_{b}$ and $\left\{r_{a}, r_{b}\right\}>d$. Note that if $r_{a} \approx r_{b} \approx d$, both members of eq. (13) would equal $d$, however this condition is never met because $\left\{\mathrm{r}_{1}, \mathrm{r}_{2}, \mathrm{r}_{3}, \mathrm{r}_{4}\right\}>\mathrm{d}$. If $\left\{r_{a}, r_{b}\right\}>>d$, then $2 r_{a}-d \approx 2 r_{a}, 2 r_{b}-d \approx 2 r_{b},\left(r_{a}-d\right) \approx r_{a}$ and $\left(r_{b}-\right.$ $\mathrm{d}) \approx \mathrm{r}_{\mathrm{b}}$, eq. (13) can - as an alternative for eq. (14) - be substituted by $r_{b}>r_{a}$.

If $\left[a_{i} / a_{e}\right]_{1}$ does not equal $\left[a_{i} / a_{e}\right]_{2}$, a change in ranking is observed if $\mathrm{R}_{1}=\mathrm{R}_{2}$ or if $\mathrm{R}_{1}<\mathrm{R}_{2}$. Let the relation between $\left[\mathrm{a}_{\mathrm{i}}\right]$ $\left.\mathrm{a}_{\mathrm{e}}\right]_{1}$ and $\left[\mathrm{a}_{\mathrm{i}} / \mathrm{a}_{\mathrm{e}}\right]_{2}$ be described by

$$
\left[\frac{a_{i}}{a_{e}}\right]_{1} \times\left[\frac{a_{i}}{a_{e}}\right]_{2}^{-1}=g
$$


The equality of $R_{1}$ and $R_{2}$ will be observed if

$$
g=\frac{2 r_{a}-d}{\left(r_{a}-d\right)^{2}}=\frac{2 r_{b}-d}{\left(r_{b}-d\right)^{2}}
$$

For $g>1$, eq. (15) can be rewritten as

$$
\frac{2 r_{a}-d}{\left(r_{a}-d\right)^{2}}<\frac{2 r_{b}-d}{\left(r_{b}-d\right)^{2}}
$$

which can be rearranged into eq. (14) or - if $\left\{r_{a}, r_{b}\right\}>>d-$ into $r_{a}>r_{b}$, hence $r_{a} \neq r_{b}$. If $R_{2}$ exceeds $R_{1}$ and $g>1$, the following inequality is valid:

$$
\mathrm{g}=\frac{2 \mathrm{r}_{\mathrm{a}}-\mathrm{d}}{\left(\mathrm{r}_{\mathrm{a}}-\mathrm{d}\right)^{2}}<\frac{2 \mathrm{r}_{\mathrm{b}}-\mathrm{d}}{\left(\mathrm{r}_{\mathrm{b}}-\mathrm{d}\right)^{2}}
$$

Considering $r_{1}>r_{2}, r_{3}>r_{4}$ and $\left\{r_{2}, r_{4}\right\}>d$, it can be accepted that generally $\left\{\mathrm{r}_{\mathrm{a}}, \mathrm{r}_{\mathrm{b}}\right\}>>\mathrm{d}$; hence, eq. (16) can then be simplified into $\mathrm{g}_{\mathrm{b}}<\mathrm{r}_{\mathrm{a}}$, which implies $\mathrm{r}_{\mathrm{a}} \neq \mathrm{r}_{\mathrm{b}}$.

\section{Calculation example}

In Fig. 6, four sample forest patches are shown, taken from the Biological Value Map 24 3/4 (De Blust et al. 1985). This map depicts a sector of a fragmented landscape situated in the Campine region (NE Belgium). Patches A and $B$ represent poplar plantations, while patches $C$ and $D$ are characterized by a mix of coniferous and deciduous species. The forest fragments are apparently different considering size, which can/will influence patch ranking, as demonstrated earlier. Evaluation by ranking of the patches as part of a conservation policy is preferably based upon $\mathrm{a}_{\mathrm{i}} / \mathrm{a}_{\mathrm{e}}$ and $R$. The calculation results for $\mathrm{d}=2$ are given in Table 1 . The ratio $\mathrm{a}_{\mathrm{i}} / \mathrm{a}_{\mathrm{e}}$ is calculated using a geographic information

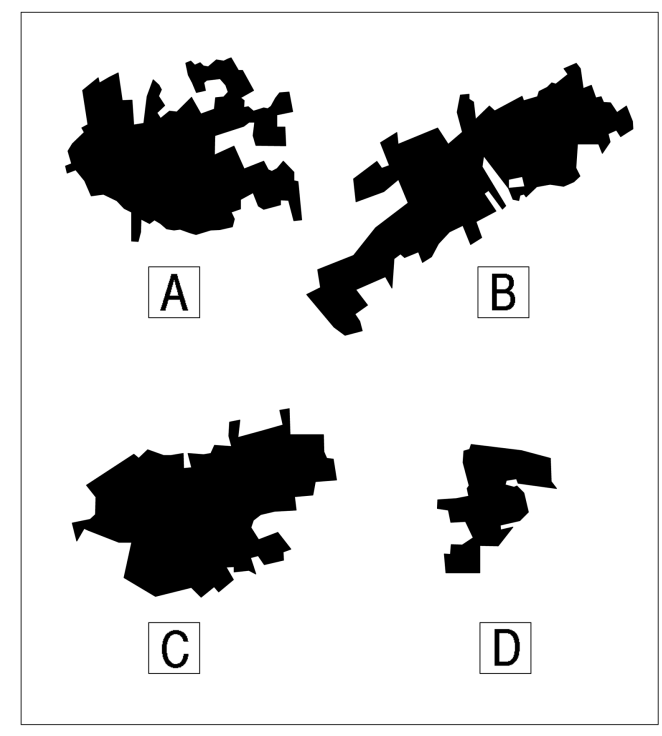

Fig. 6. Calculation example: four forest patches in the Belgian Campine region (Biological Value map 24 3/4).
Table 1. Calculation results for four forest patches in the Belgian Campine region.

\begin{tabular}{lccc}
\hline Patch & Area (pixels) & $\mathrm{a}_{\mathrm{i}} / \mathrm{a}_{\mathrm{e}}$ & $\mathrm{R}$ \\
\hline $\mathrm{A}$ & 3541 & 2.02 & 0.26 \\
$\mathrm{~B}$ & 4011 & 2.07 & 0.25 \\
$\mathrm{C}$ & 3737 & 3.39 & 0.43 \\
$\mathrm{D}$ & 1104 & 1.39 & 0.35 \\
\hline
\end{tabular}

system GRASS 4.2.1 (Anon. 1998). The ranking based upon $a_{i} / a_{e}$ gives priority to patch $C$, followed by $B, A$ and D. Note that patch $C$ is not the largest patch, which indicates that other patch features, e.g. shape (elongatedness) and perimeter curvature, are considered. If $\mathrm{R}$ is calculated, the ranking is changed significantly: the smallest patch $\mathrm{D}$ is placed second, notwithstanding its size, and the largest (B) is placed fourth. It should also be noted that for no patch $\mathrm{R}>0.5$ is observed, indicating a high presence of edge, probably a consequence of the perimeter convolution present in all patches. This latter kind of information of the normalized index $\mathrm{R}$, different from patch area and $a_{i} / a_{e}$, is the main advantage of the presented method: the absolute quantities of interior and edge habitat can be evaluated correctly. Moreover, this example shows that reserve design or selection only based on area should be executed with caution.

\section{Conclusions}

Interior-to-edge ratios are suitable to assess the status of existing patches or to compare design options by measuring the potential impact of disturbance on the patches. Large $(\mathrm{z}>>1)$, isodiametric $(k \approx 1)$ patches are characterized by the highest $a_{i} / a_{e}$. A new interior-to-edge ratio $R$ is proposed, composed of $a_{i} / a_{e}$ and a reference value, based on the most isodiametric shape for the given patch area. Six properties can be listed, based upon simulation with elliptical or rectangular shapes: 1 ) the interpretation is facilitated when $\mathrm{R}$ is compared with $\mathrm{a}_{\mathrm{i}} / \mathrm{a}_{\mathrm{e}}$, because of the fixed range $0 \leq R \leq 1 ; 2$ ) isodiametric patches are characterized by $\mathrm{R} \approx 1$, independent of their size; 3) elongated patches $(\mathrm{k}>>1)$ are characterized by lower R-values, dependent on the observed disturbance penetration depth d; 4) for a given $\mathrm{k}$ and $\mathrm{z}$, high $\mathrm{d}$-values cause low R-values; 5 ) for large patches $(\mathrm{z}>>1), \mathrm{R}$ tends towards $2(\sqrt{ } \mathrm{k} \pi /(\mathrm{k}+1)(\sqrt{ } \mathrm{c})$ and hence is dominated by $\mathrm{k}$ and 6 ) the presented $\mathrm{R}$ metric generates a ranking different from that of $\mathrm{a}_{\mathrm{i}} / \mathrm{a}_{\mathrm{e}}$ when patch sizes are unequal. The properties and advantages of $\mathrm{R}$ are exemplified using four forest fragments in the Belgian Campine region. Calculation of $\mathrm{R}$ makes correct evaluation of absolute quantities of interior and edge habitat possible. 
Acknowledgements - J. Bogaert is indebted to the Fund for Scientific Research-Flanders (Belgium) (FWO-Vlaanderen) for his fellowship as research assistant.

\section{References}

Anon. 1998. Geographic Resources Analysis Support System 4.2.1. - Baylor Univ. and OGI-USACERL.

Bogaert, J. 2000. Quantifying habitat fragmentation as a spatial process in a patch-corridor-matrix landscape model. - Ph.D. thesis, Univ. of Antwerp, Wilrijk, Belgium.

Bogaert, J. et al. 2000. Alternative area-perimeter ratios for measurement of 2-D shape compactness of habitats. - Appl. Math. Comput. 111: 71-85.

Chen, J. 1991. Edge effects: microclimatic pattern and biological responses in old-growth Douglas-fir forests. - Ph.D. thesis, Univ. of Washington, Seattle, USA.

Collinge, S. K. 1996. Ecological consequences of habitat fragmentation: implications for landscape architecture and planning. - Landscape Urban Plann. 36: 59-77.

Crow, T. R. and Gustafson, E. J. 1997. Concepts and methods of ecosystem management: lessons from landscape ecology. In: Boyce, M. S. and Haney, A. (eds), Ecosystem management: applications for sustainable forest and wildlife resources. Yale Univ. Press, pp. 54-67.

Davidson, C. 1998. Issues in measuring landscape fragmentation. - Wildl. Soc. B. 26: 32-37.

De Blust, G. et al. 1985. Biologische waarderingskaart van Belgie: algemene verklarende tekst. - Belgisch Ministerie van Volksgezondheid en het Gezin.

Diamond, J. M. 1975. The island dilemma: lessons of modern biogeographic studies for the design of natural reserves. Biol. Conserv. 7: 129-146.
Donovan, T. M. et al. 1997. Variations in local-scale edge effects: mechanisms and landscape context. - Ecology 78: 2064 2075.

Forman, R. T. T. 1981. Interaction among landscape elements: a core of landscape ecology. - In: -Tjallingii, S. P. and de Veer, A. A. (eds), Proc. Int. Congr. organized by the Netherlands Soc. for Landscape Ecol. (Veldhoven). Pudoc, pp. 35-48.

Forman, R. T. T. 1997. Land mosaics: the ecology of landscapes and regions. - Cambridge Univ. Press.

Forman, R. T. T. and Godron, M. 1986. Landscape ecology. Wiley.

Groom, M. J. and Schumaker, N. 1993. Evaluating landscape change: patterns of worldwide deforestation and local fragmentation. - In: Kareiva, P. M. et al. (eds), Biotic interactions and global change. Sinauer, pp. 24-44.

Gustafson, E. J. 1998. Quantifying landscape spatial pattern: what is the state of the art? - Ecosystems 1: 143-156.

Laurance, W. F. and Yensen, E. 1991. Predicting the impacts of edge effects in fragmented habitats. - Biol. Conserv. 55: 7792.

Laurance, W. F. et al. 1998. Rain forest fragmentation and the dynamics of Amazonian tree communities. - Ecology 79: 2032-2040.

Saunders, D. A., Hobbs, R. J. and Margules, C. R. 1991. Biological consequences of ecosystem fragmentation: a review. Conserv. Biol. 5: 18-32.

Selby, S. M. 1975. Standard mathematical tables. - CRC Press.

Spies, T. A., Ripple, W. J. and Bradshaw, G. A. 1994. Dynamics and pattern of a managed coniferous forest landscape in $\mathrm{Or}$ egon. - Ecol. Appl. 4: 555-568. 